never, under any circumstances, becoming naturally infected.

Board of Health Laboratory,

$$
\text { S. T. Darling }
$$

AnCon, Canal Zone

\section{A REQUEST FROM THE AMERICAN SOCIETY OF NATURALISTS}

The American Society of Naturalists does not possess a complete set of its published "Records." It has no copy of Part IV., Volume II. The secretary wishes to complete at least one set of the "Records" to be deposited with other material at the Wistar Institute.

Several complete sets may be made up if copies of the following can be obtained:

Volume I., Parts II., III., IV., V., VII., VIII., IX. and XI.

Volume II., Parts I., II., IV., V., VI. and VII.

Members of the society are therefore asked to look through their papers and to write to the secretary if they can supply any of the parts desired.

$$
\begin{aligned}
& \text { Bradley Moore Davis, } \\
& \text { Secretary for } 1913
\end{aligned}
$$

THE FACTS ABOUT THE ACCOUNTS OF LEARNED

$$
\text { SOCIETIES }
$$

To THE Editor of Science: The article by Professor Hart in ScIence for January 10 contains errors that need correction. The financial report of the American Academy of Political and Social Science for the year 1910 has been compared with the reports of the other societies for 1911, although the Academy's financial statement for 1911 was printed in May, 1912, eight months before Professor Hart's article appeared.

The apparent discrepancy between membership list and paying members is due to the fact that Professor Hart fails to take into account the 128 life members and 503 subscribers of the Academy represented mainly by libraries and other institutions not eligible to membership.
The statement is made in the article that the expenditure of the Academy, per paying member, was $\$ 6.71$ for the year 1910 . This calculation is not based on the true figures for membership, and suppresses the fact that $\$ 10,493.00$ was received from subscriptions to publications by non-members, from sales of current numbers, from special contributions and from life-membership fees.

The number of pages published during the year 1910 is said to be 1,523 when in fact 2,034 pages were printed. The number of words published in 1910 was 1,176,650 and not 685,000 , as stated in the article.

The details are as follows:

37,300 copies of Annals issued in 1910.

1,500 copies of Annals reprinted.

10,700 copies of a Child Labor supplement.

27,800 copies of four issues of supplements.

9,500 copies of reprints.

The average cost of printing per 1,000 . words was $\$ 16.37$, and not $\$ 32.50$, but included in this cost are items not directly chargeable to the printing of the Annals, as will be seen by the enumeration in the report.

Such are the facts about the American Academy. Professor Hart's statements about the American Historical Association are also incorrect. The proceedings are printed and sent out at government expense, and hence it has no postage bills of this sort in its accounts. The association does not print its own magazine, but has a contract with a publishing house which issues it at a net rate to the members of the association. The receipts for advertising and subscriptions are thus not accounted for in the report of the society, nor does it contain the bills for postage and for clerical help employed by the publishing house. These net costs can not fairly be compared with the gross costs tabulated in the annual report of the American Academy.

Simon N. Patten

IS THE "ACADEMIC COSTUME" WORTH WHILE?

To the Epitor of Science: I shall not attempt to answer the above question, raised by Professor Wilder in your issue of January 31. But if the question had been worded "Is 
the academic costume worth paying $\$ 35$ to $\$ 95$ for?" I would quickly answer "No." Considering it desirable to provide myself with a doctor's gown and hood, I purchased the silk and velvet trimming by the yard, and got a dressmaker to make the gown after the pattern of one owned by a friend. As a result I have a first-class gown of the best material, and the cost was about half the regular price of a similar gown ready made.

J.

\section{SCIENTIFIC BOOKS}

Michigan Bird Life, a List of the Bird Species known to Occur in the State Together With an Outline of their Classification and an Account of the Life History of Each Species, with Special Reference to its Relation to Agriculture. With seventy-five full page plates and one hundred and fiftytwo text figures. By WALTER BradFond Barrows, S.B., Professor of Zoology and Physiology and Curator of the General Museum. Special Bulletin of the Department of Zoology and Physiology of the Michigan Agriculture College. Published by the Michigan Agricultural College. 1912. 8vo. Pp. xiv $+822,70$ half-tone plates and 152 text figures.

The purpose and general character of the present work are stated by the author to be to provide an authoritative list of the birds of Michigan, with such additional information respecting them as would be useful and of interest not only to the nature lover and general reader, but to students and teachers. In a work originating with and published by a State Agricultural College, it is eminently proper that special attention should be given to the economic status of the species in relation to man's interests, yet it is recognized that each has " a scientific, an esthetic, a human value, which can not be estimated in dollars and cents," and which should forever protect it "from extreme persecution, and above all from final extinction."

An introduction of nearly thirty pages deals with the physiographic and climatic features of the state, the distribution of its plant and animal life, and especially its bird life with reference to the different areas characterized by special conditions of environment, as prairies, marshes and pine and hardwood forests. The subject "how to study birds" is discussed at some length, and with intelligence and fairness, the conclusion being that field-glass records of rare species by amateurs should not be relied upon as satisfactory evidences of occurrence. Where there is any improbability of a bird being at a given time and place, the record should " rest upon an actual specimen taken at that locality and either preserved for the examination of any one interested or at least examined and identified by a competent authority before being destroyed."

Nearly ten pages are given to the subject of migration, which includes not only comment on the migratory movements of birds in Michigan, but a summary of recent progress in knowledge of bird migration, remarks on the rapidity of flight in birds, and on the disasters known to overtake birds in migration, by which thousands upon thousands lose their lives through adverse weather conditions, so that large areas become nearly depopulated of certain species. Attention is also called to recent changes in the bird life of Michigan through deforestation of large portions of the state, the draining of marshes, etc., and the consequent increase or decrease of certain species.

The main text of the work treats, in systematic sequence, of the 326 species of birds known to occur in the state, with keys to the species and higher groups, a liberal amount of biographical matter, followed by diagnoses in small type. The life histories are especially full, with often somewhat extended discussion of the economic relations of the species to agriculture, for which the author is especially fitted by his twenty-five years of study of the complex relations of birds to insects and crops as a specialist in this field, first under the United States Department of Agriculture and later at Michigan Agricultural College. A "hypothetical list" of 62 species of birds that have been attributed to Michigan by previous 